\title{
PELATIHAN PLS-SEM MENGGUNAKAN SMARTPLS 3.0 DOSEN MATA KULIAH STATISTIKA FISIP UIN SUNAN GUNUNG DJATI BANDUNG
}

\author{
Reny Rian Marliana ${ }^{1}$ \\ ${ }^{1}$ Universitas Sebelas April \\ ${ }^{1}$ korespondensi : renyrianmarliana@gmail.com
}

\begin{abstract}
ABSTRAK
Statistika memiliki peranan yang sangat penting pada sebuah penelitian. Dengan meningkatkan kompetensi di bidang Statistika, para peneliti akan mampu meminimumkan kesalahan yang dapat terjadi dan dapat meningkatkan kualitas output penelitian. Berdasarkan observasi, masih banyak dosen atau peneliti yang terpaku pada metode analisis tertentu dalam mengolah dan menguji hipotesis penelitian dari data yang dikumpulkan melalui sebuah kuesioner. Salah satu penyebabnya adalah kurangnya pemahaman dan kemampuan dalam menerapkan dan mengolah data menggunakan metode yang sesuai dengan karakteristik data yang dimiliki baik secara teori maupun secara praktik menggunakan software. Tujuan dari kegiatan ini adalah untuk memberikan pelatihan mengenai metode PLS-SEM menggunakan SmartPLS 3.0 dalam mengolah data yang diperoleh dari kuesioner pada Dosen mata kuliah Statistika di Fakultas Ilmu Sosial dan Ilmu Politik UIN Sunan Gunung Djati Bandung. Dalam pelatihan ini, peserta dibekali dengan pemaparan teori PLS-SEM meliputi tentang pemaparan atau review mapping metode analisis data, skala pengukuran variabel, teori dasar dari PLS-SEM serta praktikum menggunakan SmartPLS 3.0. Kegiatan ini mampu mengenalkan dan meningkatkan pemahaman serta kemampuan Dosen mata kuliah Statistika di Fakultas Ilmu Sosial dan Ilmu Politik UIN Sunan Gunung Djati Bandung dalam menerapkan metode PLS-SEM menggunakan SmartPLS 3.0. Dengan demikian, kegiatan ini juga mampu mendorong motivasi dosen dalam melaksanakan penelitian dan pengembangan transfer ilmu kepada mahasiswa.
\end{abstract}

Kata kunci: pls-sem, smartpls3, abdimas, workshop

\begin{abstract}
Statistics has a very important role in a study. By increasing Statistics competence, researchers will be able to minimize errors and can improve the quality of research output. Based on observations, there are lecturers or researchers who tend to use certain methods on research hypotheses assessment on data which collected through questionaires. Caused by the lack of understanding and ability to choose a suitably method with the characteristics of the data both in theory and in practice using software. The aim of this activity is to provide training on the PLS-SEM method using SmartPLS 3.0 on data obtained from questionnaires for Lecturers of Statistics courses at the Faculty of Social and Political Sciences, UIN Sunan Gunung Djati Bandung. In this training, participants are provided with an explanation of PLS-SEM theory including review of mapping data analysis methods, variable measurement scales, basic theory of PLS-SEM with practical analysis using SmartPLS 3.0. Not only able to introduce and improve the understanding of Lecturers of Statistics courses at the Faculty of Social and Political Sciences UIN Sunan Gunung Djati Bandung on the application of the PLSSEM method using SmartPLS 3.0, this activity also encourage lecturers' motivation in carrying out research and developing knowledge transfer to students.
\end{abstract}

Keywords: pls-sem, smartpls3, abdimas, workshop

\section{PENDAHULUAN}

Penelitian tidak dapat dipisahkan dari dunia

Pendidikan. Hasil dari sebuah penelitian dapat berupa temuan-temuan yang mampu mendorong pengembangan ilmu dan pedoman dalam mengambil sebuah keputusan agar Pendidikan semakin maju dan berkembang [1]. Tingkat keakuratan dan kepercayan sebuah hasil penelitian bergantung pada ketepatan metodologi penelitian yang digunakan. Penelitian yang baik adalah penelitian yang 
dilakukan dengan metode ilmiah yang didasarkan pada ciri-ciri kelimuan yang rasional, sistematis dan empiris, objektif atau tidak bersifat subyektif, bukan mengungkap prasangka dan terkaan yang tidak didasarkan pada fakta [2]. Untuk mampu memahami dan menentukan metode ilmiah atau metode penelitian yang tepat, seorang peneliti dituntut untuk mampu mendalami atau memahami Statistika.

Statistika adalah pengetahuan mengenai bagaimana cara mengumpulkan, mengolah, menyajikan, analisis, menarik kesimpulan dan interpretasi dari sebuah data yang diperlukan dalam menyusun sebuah keputusan [3]. Statistika merupakan cabang dari metode ilmiah yang membahas tentang desain eksperimen, survey melalui sampling, investigasi dan inferensi statistika untuk memperoleh informasi tertentu dalam pengujian hipotesis tentang sebuah populasi [2]. Statistika dapat meminimumkan kesalahan yang dapat terjadi pada sebuah penelitian [4]. Dengan demikian jelas bahwa Statistika memiliki peran yang sangat penting dalam bidang Pendidikan dan penelitian.

Peran Statistika dapat maksimal jika seorang peneliti mampu menguasai teknis dan prosedur kerja di bidang Statistika [4]. Selain sebagai seorang peneliti, Dosen memiliki peran sebagai ujung tombak dalam transfer ilmu terhadap mahasiswa. Oleh karena itu, dosen dituntut untuk melaksanakan pengembangan kompetensi diri yang dapat menunjang pelaksanaan penelitian maupun Pendidikan yang dalam hal ini adalah kompetensi di bidang Statistika.

Salah satu metode analisis data yang saat ini sedang mengalami perkembangan pesat adalah Partial Least Squares-Structural Equation Modeling (PLS-SEM). PLS-SEM merupakan sebuah metode statistika non-parametrik yang tidak memerlukan asumsi distribusi pada sebuah data dan dapat digunakan pada data yang tidak berdistribusi normal dengan ukuran sampel kecil [5]-[7]. PLS-SEM merupakan salah satu metode yang tepat digunakan ketika data yang dimiliki merupakan data yang dikumpulkan melalui sebuah kuesioner.

Berdasarkan pengamatan yang dilakukan, selama ini masih banyak dosen-dosen atau peneliti yang terpaku pada metode analisis tertentu terutama analisis regresi linear, korelasi pearson dan statistika deskriptif dalam mengolah dan menguji hipotesis penelitian dari data yang dikumpulkan melalui sebuah kuesioner [7]. Hal ini disebabkan oleh kurangnya pemahaman dan kemampuan dalam menerapkan dan mengolah data menggunakan metode PLS-SEM baik secara teori maupun secara praktik menggunakan software.

Untuk itu Pimpinan Fakultas Ilmu Sosial dan Ilmu Politik UIN Sunan Gunung Djati Bandung merasa perlu untuk mengadakan workshop/pelatihan dan pendampingan dan meminta untuk membantu dalam memahami dan menerapkan metode PLS-SEM menggunakan SmartPLS 3.0 dalam mengolah data penelitian. Pelatihan seperti ini mampu meningkatkan pemahaman dosen di STMIK Pesar Nabire dalam menerapkan metode PLS- 
SEM dan memudahkan dosen dalam mengolah dan menganalisis data penelitian kuantitatif menggunakan software SmartPLS 3.0 [8]. Selain itu, pelatihan serupa mampu meningkatkan pemahaman dosen dan mahasiswa Fakultas Ekonomi Jurusan Manajemen dan Akuntansi Universitas Merdeka dalam menggunakan program SmartPLS 3.0 untuk penelitian [9].

Dengan demikian, tujuan dari pengabdian masyarakat ini adalah meningkatkan pemahaman penerapan metode PLS-SEM dalam mengolah dan menganalisis data yang dikumpulkan dari kuesioner pada Dosen mata kuliah Statistika di Fakultas Ilmu Sosial dan Ilmu Politik UIN Sunan Gunung Djati Bandung serta pendampingan praktikum pengolahan dan analisis data menggunakan software SmartPLS 3.0. Kegiatan ini diharapkan dapat meningkatkan kualitas hasil penelitian dan transfer ilmu kepada mahasiswa.

\section{METODE}

Kegiatan pengabdian masyarakat ini dilakukan melalui metode pelatihan/workshop. Kegiatan dilakukan dengan penjelasan dan pemaparan teori dan praktik mengenai PLS-SEM. Pemaparan teori PLS-SEM meliputi tentang pemaparan atau review mapping metode analisis data berdasarkan skala pengukuran pada variabel-variabel penelitian dan hipotesis penelitian yang dibentuk, pemaparan dan penjelasan lebih dalam mengenai jenis-jenis skala pengukuran variabel dalam pembentukan kuesioner penelitian, pemaparan dan penjelasan mengenai teori dasar dari PLS-SEM (karakteristik data, karakteritik model, algoritma PLS-SEM, Evaluasi model, ukuran sampel dan tahapan analisis PLS-SEM disertai dengan contoh penelitian. Selain pemaparan dan penjelasan teori, kegiatan ini dilaksanakan dengan demonstrasi dan praktikum bersama menggunakan software SmartPLS 3.0 dalam mengolah dan menguji hipotesis penelitian pada data yang dikumpulkan melalui kuesioner di Laboratorium Terpadu Gd. Solahuddin Sanusi Lt. 4, Lab. Dasar-dasar Pemograman (MTK-1) UIN Sunan Gunung Djati Bandung. Kegiatan ini diikuti oleh 17 orang Dosen mata kuliah Statistika di Fakultas Ilmu Sosial dan Ilmu Politik UIN Sunan Gunung Djati Bandung.

\section{HASIL DAN PEMBAHASAN}

Pada kegiatan ini peserta dibekali dengan pemaparan dan penjelasan materi dalam beberapa tahap dengan tujuan peserta dapat memahami teknis dan prosedur kerja mengenai penerapan analisis PLS-SEM dalam penelitian. 
P-ISSN: 2745-5912

E-ISSN: 2745-9047

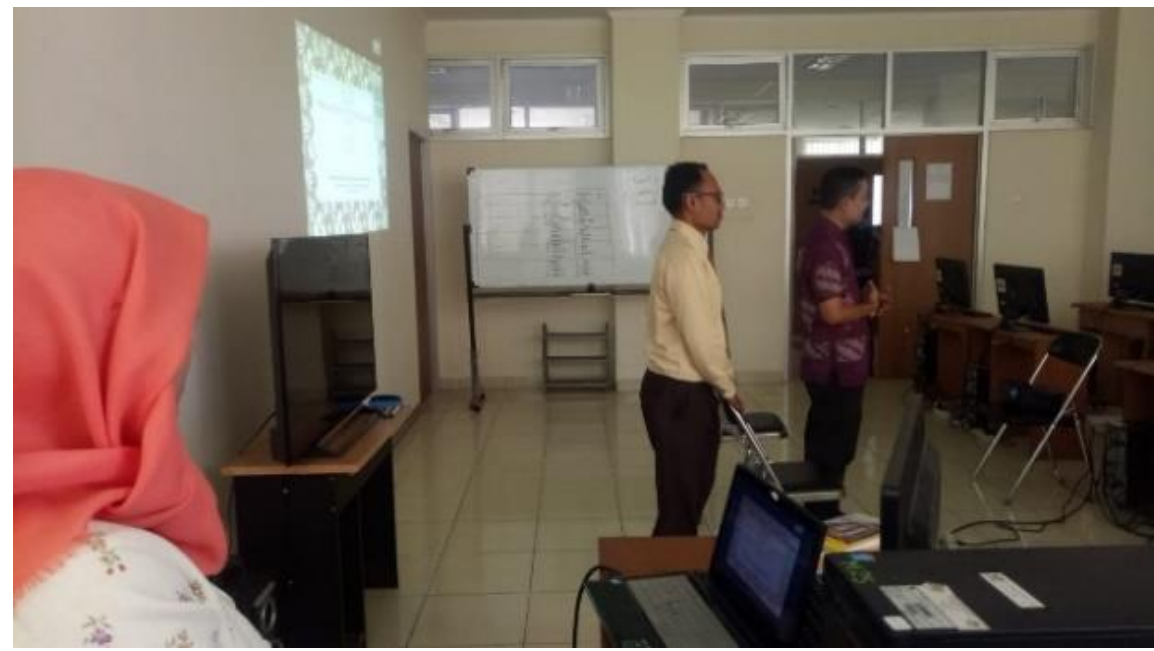

Gambar 1 : Perkenalan sebagai Narasumber

Kegiatan dilaksanakan selama satu hari pada 16 Oktober 2019 pukul 11.00 s.d. 13.00 WIB bertempat di Laboratorium Terpadu Gd. Solahuddin Sanusi Lt. 4, Lab. Dasar-dasar
Pemograman (MTK-1) UIN Sunan Gunung Djati Bandung sesuai dengan surat undangan sebagai narasumber Nomor B555/Un.05/III.8/KS.0.2/10/2019.

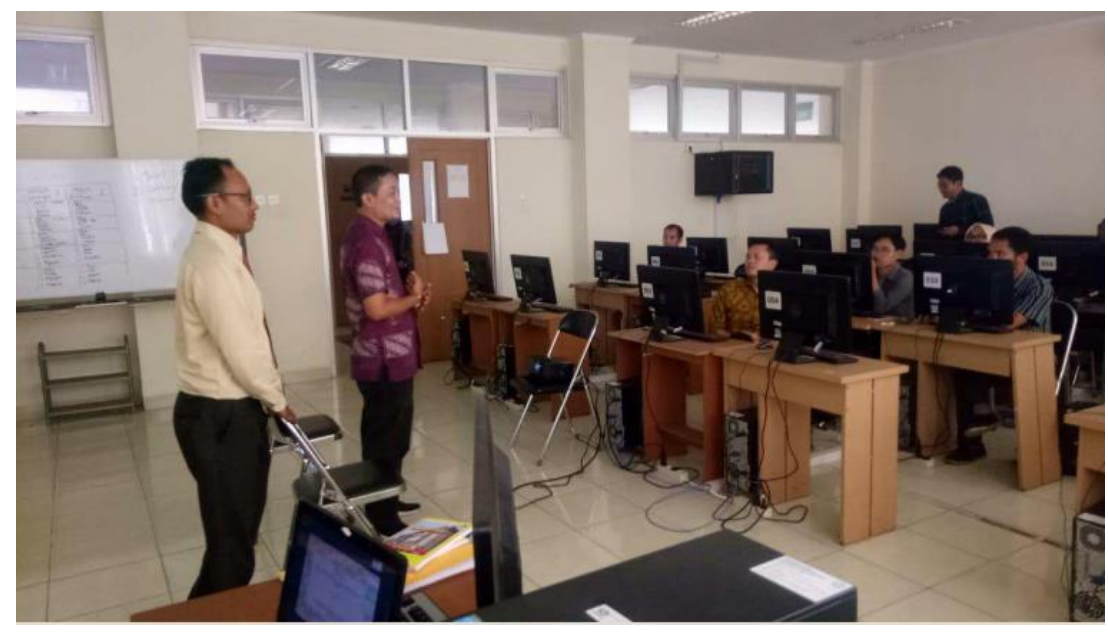

Gambar 2 : Sambutan dari Pimpinan Fakultas Ilmu Sosial dan Ilmu Politik UIN Sunan Gunung Djati Bandung

Tahap pertama, peserta dibekali dengan penelitian. Tujuannya adalah peserta mampu pemaparan mengenai mapping (Gambar 1) menentukan metode analisis data yang tepat analisis data berdasarkan jenis skala pada penelitian yang dilakukan berdasarkan pengukuran yang digunakan pada data skala pengukuran variabel pada data. 


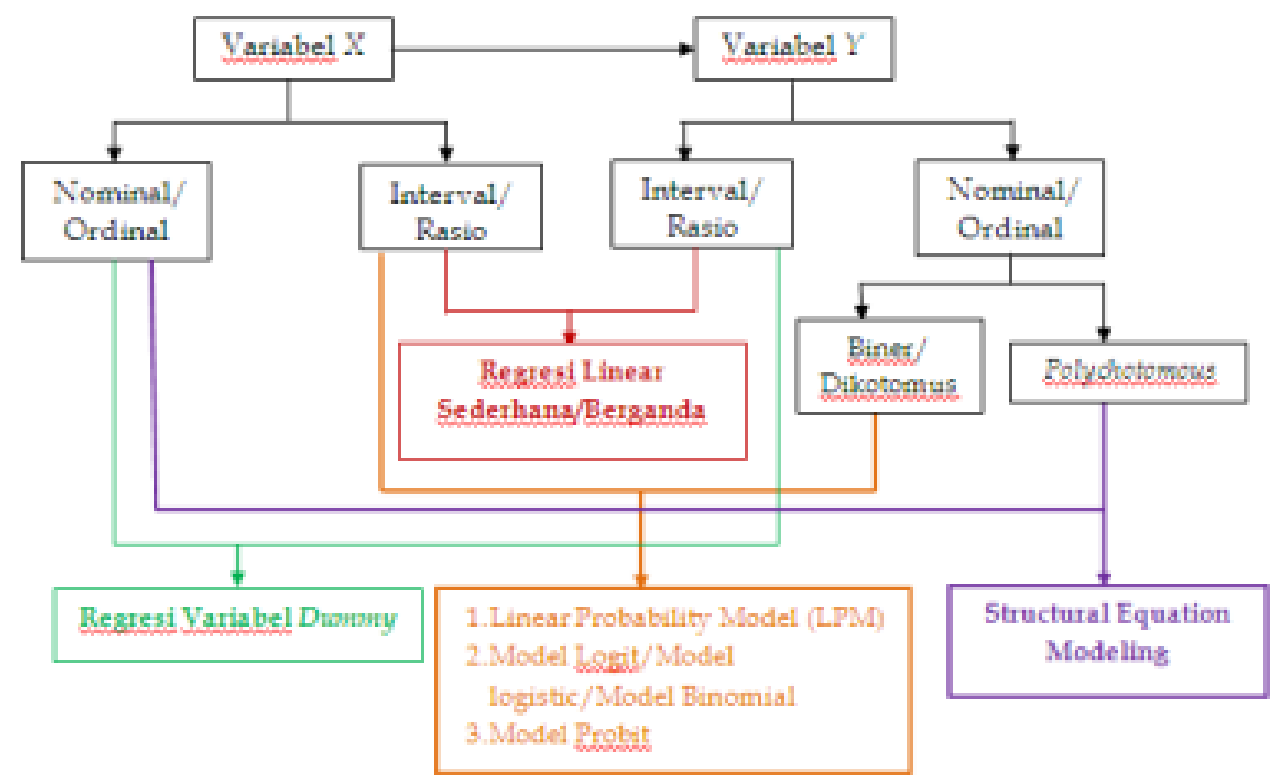

Gambar 3 : Mapping Analisis Data

Untuk meningkatkan kembali pemahaman mengenai skala pengukuran variabel dalam pembentukan kuesioner, maka pada tahap kedua, peserta dibekali dengan pemaparan dan penjelasan mengenai skala nominal, skala ordinal, skala interval, skala rasio, skala likert, skala Guttman, Semantic differensial dan rating scale yang disertai dengan contohnya.

Pemaparan mengenai mapping analisis data dan skala pengukuran variabel dapat dengan mudah dipahami oleh peserta, sehingga pada tahap ini tidak ada kendala yang ditemui.

Pada tahap ketiga, peserta diberikan penjelasan dan pemaparan teori dasar mengenai PLSSEM. Pemaparan dimulai dengan penjelasan mengenai PLS-SEM merupakan bagian dari Teknik Multivariat Structural Equation Modeling (SEM) dan uraian tentang perbedaan PLS-SEM dengan Covariance Based-SEM (CB-SEM) dan kelebihan PLS-SEM dibandingkan dengan CB-SEM. Kemudian dilanjutkan dengan pemaparan dan penjelasan mengenai karakteristik data, karakteristik model, algoritma PLS-SEM, evaluasi model (evaluasi model pengukuran dan model struktural), penentuan ukuran sampel dan tahapan analisis (model spesifikasi, estimasi parameter model, evaluasi model pengukuran, evaluasi model struktural) pada PLS-SEM. Pemaparan yang diberikan serupa dengan pemaparan materi yang diberikan oleh Yuliawan kepada dosen di STMIK Pesar Nabire [8]. Pada tahap ini terdapat beberapa peserta yang menemui kesulitan dalam memahami beberapa teori meliputi algoritma PLS-SEM, perbedaan bentuk model pada pembentukan model spesifikasi serta pada evaluasi model pengukuran.

Untuk mengatasi kendala tersebut dan membantu peserta tersebut meningkatkan pemahamannya, kegiatan dilanjutkan dengan pemaparan dari contoh penelitian dalam penerapan PLS-SEM. Pemaparan contoh penelitian ini dimulai dengan penjelasan 
pembentukan kuesioner penelitian, critical review pada penelitian terdahulu dan pembentukan model penelitian. Selanjutnya ditunjukkan pula contoh kuesioner penelitian yang sesuai dengan karakteristik data pada PLS-SEM (pemaparan tahap kedua dan ketiga) serta penentuan metode analisis data berdasarkan pemaparan tahap pertama. Kesulitan pemahaman dalam algoritma PLSSEM dibantu dengan pemaparan contoh estimasi parameter dalam contoh penelitiannya. Kemudian kesulitan peserta pada pemahaman mengenai pembentukan model spesifikasi dibantu dengan menunjukkan dan menjelaskan bagaimana membentuk item pertanyaan pada kuesioner yang didasarkan pada indikator yang dibentuk berdasarkan referensi sesuai bidang penelitian. Sementara itu, kesulitan peserta dalam memahami evaluasi model pengukuran dibantu dengan pemaparan contoh perhitungan dan analisis evaluasi model pengukuran pada penelitian yang dijadikan sebagai contoh. Pemaparan dan penjelasan contoh peneltian tersebut mampu meningkatkan pemahaman peserta yang mengalami kesulitan pada tahap ketiga. Peningkatan pemahaman ini menunjukkan peningkatan yang serupa pada kegiatan yang dilaksanakan oleh Yuliawan [8]. Tahap terakhir pada kegiatan ini adalah praktikum pengolahan dan analisis PLS-SEM menggunakan software SmartPLS 3.0. Praktikum ini dilakukan Bersama denga demonstrasi praktikum secara bersamaan dengan peserta.

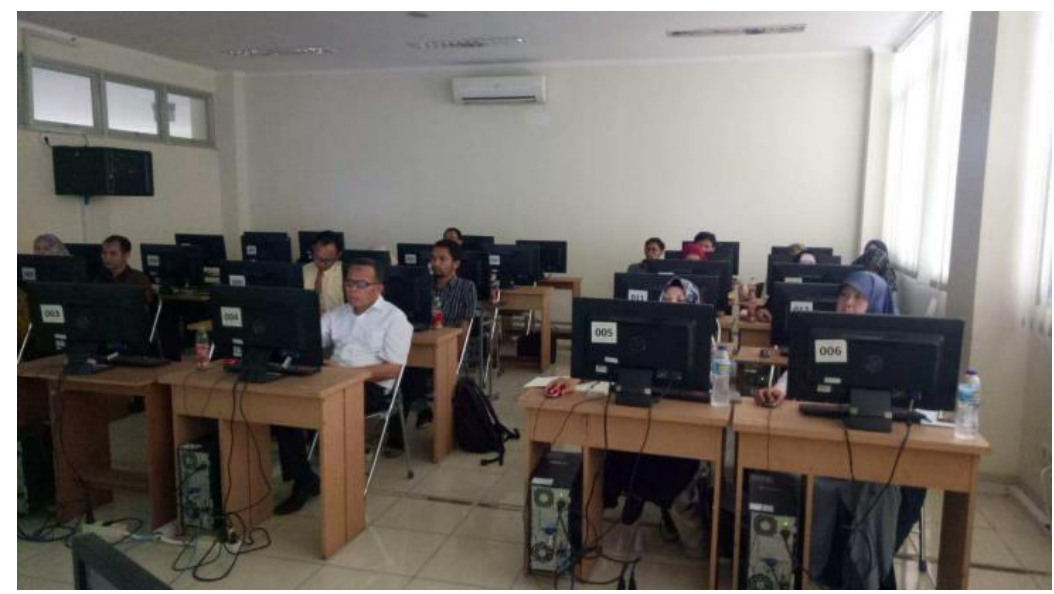

Gambar 4 : Praktikum Bersama Pengolahatan data menggunakan SmartPLS 3.0

Demonstrasi yang dilakukan disertai dengan penjelasan dan penarikan kesimpulan pada setiap tahap analisis dan langkah praktikum. Sama seperti pada tahap sebelumnya praktikum dimulai dengan langkah penyimpanan data penelitian yang diperoleh dari penyebaran kuesioner dalam format $c s v$ kemudian import data pada SmartPLS 3.0. Kemudian Langkah praktikum selanjutnya berurutan dimulai pembentukan model spesifikasi, estimasi parameter, evaluasi model pengukuran dan evaluasi model struktural serta pengambilan kesimpulan. Pada tahap ini, beberapa peserta mengalami kendala pada tahap import data dan pembentukan model spesifikasi. Kendala ini tidak terlalu berarti karena dapat diatasi dengan cepat baik oleh saya sebagai narasumber maupun dengan bantuan peserta lain yang tidak 
mengalami kendala. Kendala yang cukup berarti yang ditemui adalah software SmartPLS 3.0 yang digunakan adalah versi Student sehingga praktikum tidak optimal karena terdapat beberapa keterbatasan. Keterbatasan tersebut adalah keterbatasan ukuran sampel serta tidak dapat melakukan export output analisis dalam format excel maupun dalam bentuk $R$-Software. Kendala yang sama ditemui kegiatan serupa yang dilaksanakan oleh Budiarsi pada dosen dan mahasiswa Fakultas Ekonomi Jurusan Manajemen dan Akuntansi Universitas Merdeka [9].

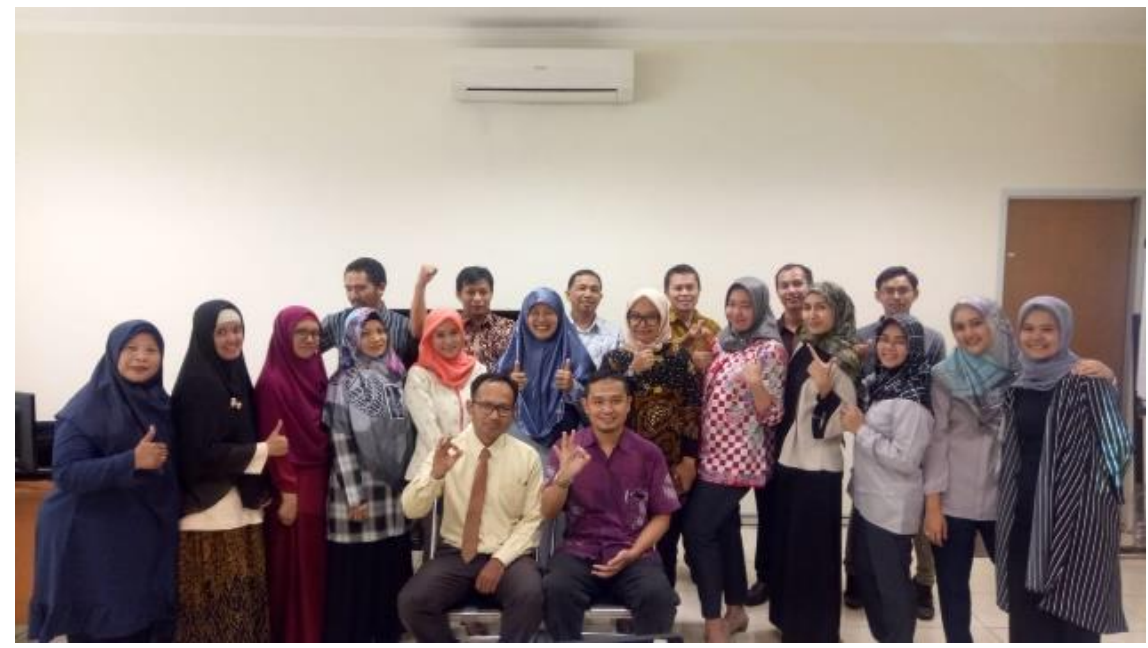

Gambar 5 : Narasumber, Peserta Pelatihan dan Pimpinan Fakultas Ilmu Sosial dan Ilmu Politik UIN Sunan Gunung Djati Bandung

\section{PENUTUP}

Kegiatan pelatihan metode PLS-SEM menggunakan SmartPLS 3.0 ini mampu mengenalkan dan meningkatkan pemahaman Dosen mata kuliah Statistika di Fakultas Ilmu Sosial dan Ilmu Politik UIN Sunan Gunung Djati Bandung pada penerapan metode PLSSEM dalam penelitian. Selain itu, kegiatan ini mampu meningkatkan kemampuan peserta dalam mengolah data penelitian menggunakan software SmartPLS 3.0. Peningkatan ini dibuktikan dengan antusias kehadiran maupun pertanyaan-pertanyaan yang diajukan peserta serta kedisiplinan peserta selama mengikuti kegiatan. Dengan adanya peningkatan tersebut, kegiatan ini diharapkan mampu mendorong motivasi Dosen mata kuliah Statistika di Fakultas Ilmu Sosial dan Ilmu Politik UIN Sunan Gunung Djati Bandung dalam melakukan penelitian, meningkatkan kualitas output penelitian dan pengembangan transfer ilmu pada mahasiswa.

Pelatihan ini perlu dilanjutkan dengan menggunakan software SmartPLS 3.0 full version agar kemampuan Dosen mata kuliah Statistika di Fakultas Ilmu Sosial dan Ilmu Politik UIN Sunan Gunung Djati Bandung dalam mengolah data penelitian menggunakan SmartPLS 3.0 dapat lebih maksimal.

\section{DAFTAR PUSTAKA}

[1] Rudini, "Peranan Statistika dalam Penelitian Sosial Kuantitatif," $J$. 
SAINTEKOM Sains, Teknologi, Komputer dan Manajemen, Vol. 6, no. 2, 2016.

[2] T. Tayeb, R. Idris, and A. Sulherah, "Peranan Mata Kuliah Statistika dalam Memahami Mata Kuliah Metodologi Penelitian bagi Mahasiswa Jurusan Pendidikan Matematika Fakultas Tarbiyah dan Keguruan UIN Alauddin Makassar," MaPan Jurnal Matematika dan Pembelajaran, Vol. 2, no. 1, pp. 105-122, 2014.

[3] R. R. Marliana, Modul 4 Probabilitas dan Statistika. Sumedang: STMIK Sumedang, 2019.

[4] I. P. Sampurna, "Peran Statistika dalam Meminimumkan Kesalahan pada Penelitian.” 2015. Available : https://simdos.unud.ac.id/uploads/file_p enelitian_1_dir/706f3626fb75be822e82 1132747e0acb.pdf

[5] R. R. Marliana and L. Nurhayati, "Covariance Based-SEM on Relationship between Digital Literacy, Use of E-Resources and Reading Culture of Students," Indonesian Journal of Statistics and Its Applications, vol. 4, no. 1, pp. 55-67,
2020.

[6] R. R. Marliana, "Partial Least SquaresStructural Equation Modeling pada Hubungan antara Tingkat Kepuasan Mahasiswa dan Kualitas Google Classroom berdasarkan Metode Webqual 4.0," Journal Matematika, Statistika dan Komputasi, vol. 16, no. 2, pp. 174-186, 2020.

[7] R. R. Marliana and L. Nurhayati, "Relationship Modeling between Digital Literacy, The Use of e-Resources and Reading Culture of Students at STMIK Sumedang using PLS-SEM," in ICONISTECH 2019, 2019.

[8] K. Yuliawan, "Pelatihan Smartpls 3.0 untuk Pengujian Hipotesis penelitian Kuantitatif," J. Pengabdian Kepada. Masyarakat, Membangun Negeri, vol. 5, no. 1, pp. 43-50, 2021.

[9] S. Y. Budiarsi, "Pendampingan Pengenalan Program SEM-PLS Pada Fakultas Ekonomi Universitas Merdeka Surabaya," Journal Abdimas PeKA, vol. 3, no. 2, pp. 126-134, 2020. 